\title{
RISK FACTORS AND OUTCOME OF INSTRUMENTAL VAGINAL DELIVERY IN BP KOIRALA INSTITUTE OF HEALTH SCIENCES
}

\author{
Dixit $B^{1^{*}}$, Manandhar $T^{1}$, Sitaula $S^{1}$, Basnet $T^{1}$
}

\section{Affiliation}

1. Assistant Professor, Obstetrics and Gynecology, BP Koirala Institute of Health Sciences, Nepal

\section{ARTICLE INFO \\ Article History \\ Received : 08 March, 2019 \\ Accepted : 28July, 2019 \\ Published : 31 August, 2019}

(C) Authors retain copyright and grant the journal right of first publication with the work simultaneously licensed under Creative Commons Attribution License CC - BY 4.0 that allows others to share the work with an acknowledgment of the work's authorship and initial publication in this journal.

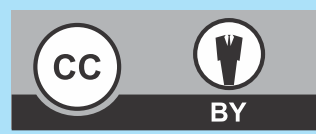

ORA 116

DOI: http://dx.doi.org/10.3126/bjhs.v4i2.25438

\author{
* Corresponding Author \\ Dr Baburam Dixit (Thapa) \\ Assistant Professor \\ Obstetrics and Gynecology \\ BP Koirala Institute of Health Sciences, Nepal \\ Email ID: baburamdixit@yahoo.com \\ ORCID ID: https://orcid.org/0000-0002-4412-2689
}

\section{Citation}

Dixit B, Manandhar T, Sitaula S, Basnet T. Risk Factors and Outcome of Instrumental Vaginal Delivery in BP Koirala Institute of Health Sciences. BJHS 2019;4(2)9: 697- 701.

\section{ABSTRACT}

\section{Introduction}

Delivery which is conducted with the help of instruments either vacuum or Forceps is known as instrumental vaginal delivery (IVD). It is done to prevent the patient from impending cesarean section and uterine scar which has its implication in the future pregnancy along with maternal and fetal morbidities as well.

\section{Objective}

This study assessed the risk factors and feto-maternal outcome of instrumental vaginal delivery

\section{Methodology}

This was a retrospective study carried out on all patients that had IVD between Baisakh 01, 2075 and Chaitra 31, 2075. The instrumental delivery was by vacuum only as we don't practice forceps delivery in our hospital. Data were obtained from the hospital records which included the age, parity, booking status, type of procedure performed, the APGAR scores of the babies and complications in the parturient. The data were analyzed for significance using SPSS software 11.5.

\section{Results}

Total delivery during one year period was 10,818 . Among them 7032 had vaginal delivery and 3786 underwent cesarean section. There were $260(2.4 \%)$ instrumental delivery which were all vacuum assisted vaginal delivery. Mean age of the patients was 26 years old and most of them were nulliparous. The most common indication for instrumental delivery was prolonged $2^{\text {nd }}$ stage of labor accounting for about $36.1 \%$. Other common indications were fetal bradycardia, meconium stained liquor, heart disease, eclampsia and anemia. Seven patients had postpartum hemorrhage and three patients had $3^{\text {rd }}$ or $4^{\text {th }}$ degree perineal tear. Among the baby delivered $14.6 \%$ had low APGAR at five minute and nine were still birth.

\section{Conclusion}

Instrumental vaginal delivery is a safe procedure to decrease the increasing rate of cesarean section although it may be associated with maternal and fetal morbidities.

\section{KEYWORDS}

Cesarean section, Instrumental Vaginal Delivery, Postpartum hemorrhage. 


\section{INTRODUCTION}

Delivery which is conducted with the help of instruments either vacuum or Forceps is known as instrumental vaginal delivery (IVD). It is done to prevent the patient from impending cesarean section in second stage of labor. A successful instrumental assisted delivery avoids cesarean section, its scar in uterus and the future implications. ${ }^{1}$ The incidence of instrumental vaginal delivery in low resource countries like Nepal is low because of lack of epidural analgesia and continuous electronic fetal monitoring but in developed countries it can range from 5-15\%. ${ }^{2,3}$

World Health Organization (WHO) has included instrumental vaginal delivery in basic emergency obstetric care. ${ }^{4}$ The rise in rate of cesarean section is becoming a great challenge worldwide. The morbidity and mortality from IVD is difficult to estimate as complications often lead to these procedures. IVD is used mostly either prolonged $2^{\text {nd }}$ stage of labor or suspected fetal compromise in $2^{\text {nd }}$ stage of labor. Other common indications are usually done to short cut second stage of labor like pregnancy with heart disease, severe pre eclampsia, eclampsia, anemia in pregnancy, poor maternal effort and previous history of lower segment cesarean section or uterine surgeries. Failure to progress in $2^{\text {nd }}$ stage of labor may be due to mal position of the fetal head, ineffective uterine contractions or feto-pelvic disproportion. Recent UK NICE guideline recommended that the second stage is prolonged when it crosses two hours in primigravida and one hour in multigravida. Because of better fetal monitoring, fewer women reach the second stage and also the surgeons prefer cesarean section instead of rotational or mid cavity IVD. ${ }^{2}$ IVDs are associated with different maternal and fetal morbidities. Mother can have postpartum hemorrhage, extended perineal tear, $3^{\text {rd }} / 4^{\text {th }}$ degree perineal tear, para urethral tear and cervical tear. The failure of IVD needing cesarean section varies according to the studies.,

The choice of which instrument to use depends on the perception of practitioners on the relative safety of the instruments and their experiences. It varies from one hospital to another and one country to another. In some areas it depends on the availability of the instruments and the skill of the attending doctor. In United States vacuum delivery is preferred where as in Europe forceps delivery is preferred. ${ }^{7}$ Different studies have been done to compare the vacuum assisted vaginal delivery and forceps delivery with varied results. But most of them have found to have more fetal complications with vacuum delivery and more maternal complications with forceps delivery. ${ }^{8,9}$ Due to various reasons it is underused in low resource settings. There is either lack of skill or lack of instruments or both. ${ }^{1}$ In Nepal vacuum assisted vaginal delivery is preferred over forceps delivery. ${ }^{10}$

\section{METHODOLOGY}

This is a retrospective study carried out on all patients that had undergone instrumental vaginal delivery between Baisakh 01, 2075 and Chaitra 31, 2075 in the labor room of BP Koirala institute of Health Sciences (BPKIHS). After taking clearance from Institutional Review Committee (IRC) of BPKIHS, case file records were collected from hospital records section. Data were obtained from the hospital records which included the age, parity, booking status and type of procedure performed. Risk factors noted were baby weight, prolonged augmentation, booking status and body mass index (BMI). Maternal outcomes assessed were postpartum hemorrhage, $3^{\text {rd }} / 4^{\text {th }}$ degree perineal tear, extended episiotomy and failed vacuum delivery. Fetal outcomes assessed were Apgar score at 5 minutes, still birth and NICU admission. Data were collected in pre designed proforma and entered in MS-Excel chart and converted to SPSS software for final analysis. Categorical variables were described using frequency distribution and percentages. Continuous variables were expressed by means and standard deviations.

\section{RESULTS}

Total number of delivery during the study period of one year was 10,818 . Among them vaginal delivery was 7032 and cesarean section was 3786 . Total instrumental vaginal delivery (Vacuum assisted vaginal delivery) during the period was 260 which were about $2.4 \%$ of total delivery and $3.69 \%$ of vaginal delivery. All the instrumental vaginal delivery was by Vacuum assisted vaginal delivery. There were no forceps deliveries conducted in BPKIHS during the study period.

Table 1 shows the baseline characteristics of patients with instrumental vaginal delivery. The total patients in the age group $20-29$ were $76 \%$. Among them $10.4 \%$ was teen pregnancy. The mean age of the patient was 24 years. Majority of the patients were nullipara (63.5\%). Only $38.4 \%$ patients were booked among the total patients.

Table 2 shows the risk factors for instrumental vaginal delivery. Common risk factors seen in the study were nulliparity, unbooked patients, prolonged augmentation of more than eight hours and birth weight of more than $3.5 \mathrm{~kg}$. Table 3 shows the indications for instrumental vaginal delivery. The most common cause for instrumental delivery was prolonged $2^{\text {nd }}$ stage of labor followed by meconium stained liquor and fetal bradycardia. Other factors include heart disease, anemia, eclampsia, poor maternal effort and previous lower segment cesarean section.

There were different complications associated with Instrumental vaginal delivery. Table 4 shows different complications after instrumental vaginal delivery. Seven patients had postpartum hemorrhage, four had extended vaginal tear and three had either $3^{\text {rd }}$ or $4^{\text {th }}$ degree vaginal tear needing repair in operation theatre. The failure of instrumental vaginal deliveries is not rare. They may be due to different reasons. In our study four $(1.5 \%)$ patients had cesarean section for failed vacuum delivery. There was no maternal mortality after the vacuum delivery.

Table 5 shows the fetal outcome of vacuum delivery. APGAR score at 5 minutes $<6$ was found in $13.6 \%$ patients. Among the total babies, 34 (13\%) were admitted in NICU. There were nine still births. 
Table 1: Baseline characteristics of the patients $(n=260)$

$\begin{array}{cccc}\text { Characterstics } & \text { Frequency } & \text { Percentage (\%) } \\ \text { Age: } & <20 & 25 & 9.6 \\ & 20-29 & 172 & 66.1 \\ & 30-39 & 59 & 22.6 \\ & \geq 40 & 04 & 1.5 \\ \text { Parity: } & \text { Nullipara } & 186 & 71.5 \\ & \text { Primipara } & 48 & 18.4 \\ \text { Multipara } & 26 & 10.1 \\ \text { Booking Status } & & \\ \text { Booked } & 100 & 38.4 \\ \text { Unbooked } & 160 & 61.6\end{array}$

\begin{tabular}{|c|c|c|}
\hline Risk Factors & Frequency & Percentage (\%) \\
\hline Nulliparity & 186 & 71.5 \\
\hline Booking status (Unbooked) & 160 & 61.5 \\
\hline Prolonged augmentation (>8hrs) & 174 & 66.9 \\
\hline Birth weight (>3.5 kg) & 179 & 68.8 \\
\hline
\end{tabular}

Table 3: Indication of instrumental vaginal delivery

$\begin{array}{lr}\text { Indication } & \text { Frequency (\%) } \\ \text { Prolonged } 2^{\text {nd }} \text { stage of labor } & 94(36.1) \\ \text { Meconium stained liquor } & 67(25.7) \\ \text { Fetal Bradycardia } & 61(23.4) \\ \text { Pre-eclampsia/ eclampsia } & 12(4.6) \\ \text { Heart disease } & 6(2.3) \\ \text { Anemia } & 3(1.1) \\ \text { Poor maternal effort } & 6(2.3) \\ \text { Previous lower segment cesarean section } & 13(5)\end{array}$

Table 4: Complications of instrumental vaginal delivery Complications Frequency (\%)

Postpartum hemorrhage

Extended vaginal tear

$3^{\text {rd }} / 4^{\text {th }}$ degree tear

Paraurethral tear

Cervical tear

Failed instrumental delivery

$4(1.5 \%)$

\section{Table 5: Fetal outcome}

Fetal outcome

Frequency (\%)

APGAR score at $5 \mathrm{~min}<6$

38 (14.6)

Still birth

9 (3.4)

NICU admission

34 (13)

cephalohematoma

$10(3.8 \%)$

\section{DISCUSSION}

Instrumental vaginal deliveries are not a substitute for caesarean delivery; they are safe obstetric practices where benefits outweigh the risks when protocols are followed.
The alarming rise of cesarean section rate is an upcoming challenge in obstetrics. Among different strategies, Instrumental delivery is one of the measures to decrease the rate of cesarean section. It needs good skill and practice to decrease the failure of instrumental vaginal delivery as well as maternal and fetal morbidities and mortalities.

Total number of vacuum delivery in BPKIHS in one year study period was 260 which account about $2.4 \%$ of all the deliveries. The most common cause of vacuum delivery was prolonged $2^{\text {nd }}$ stage of labor (36.1\%) followed by meconium stained liquor (25.7\%). Seven patients had post partum hemorrhage. Among them $1.5 \%$ had failed vacuum delivery needing cesarean section. There were nine still births during the instrumental deliveries.

The incidence of instrumental vaginal delivery varies in different countries. United States have the instrumental delivery rates between 10 to $15 \%$. ${ }^{11}$ It is higher in developed countries and low in developing or poor countries. Table 6 shows incidence in different studies done in different countries.

\begin{tabular}{|c|c|c|}
\hline Study done & Country & Incidence \\
\hline Our study & Nepal & $2.4 \%$ \\
\hline Aliyu LD et al $^{12}$ & Nigeria & $0.69 \%$ \\
\hline Johanson $\mathrm{R}^{13}$ & UK & $10 \%$ \\
\hline Shameel Faisal et al $^{14}$ & India & $2.8 \%$ \\
\hline
\end{tabular}

The indications for IVDs in this study were similar to those reported elsewhere. ${ }^{8,15-16}$ The most common indication in most of the studies was prolonged second stage of labor. Other common indications are fetal distress, meconium stained liquor and other conditions like anemia, eclapsia, previous lower segment surgeries and heart disease to short cut the second stage.

The maternal and fetal morbidities in different studies are inconsistent. Our study showed postpartum hemorrhage in instrumental delivery of about $2.7 \%$, which is similar in other studies. ${ }^{12,14}$ In our study extended episiotomy tear was present in about $1.5 \%$ of the patients which was lower than the study done by Singh Abha et al. where $26.9 \%$ of the patients had extended tear. ${ }^{1}$

The $3^{\text {rd }} / 4^{\text {th }}$ degree tear in study done by CA Ameh et al ${ }^{5}$ in UK was about $2.3 \%$ where as in our study only $1.1 \%$ patients had third or fourth degree tear. The failure of instrumental delivery leading to cesarean section was about $1.5 \%$ which was similar in study very low than in the study done by Singh Abha et al $^{1}$ in India where they had $14 \%$ failure rate.

The risk of neonatal morbidities varies in different studies. The APGAR score at 5 minutes was $>6$ in $85.4 \%$ of babies delivered in our study which was similar in other studies as well. ${ }^{17,}{ }^{18}$ Rate of babies admitted in NICU is different in different studies as shown in the table 7 . The rate of still birth in our study was $3.4 \%$ which was similar in other studies as well. $^{14,19}$ 
In our study there were no forceps deliveries but RCOG guideline stated that the obstetricians should be able to perform both vacuum and forceps when needed but they also concluded that vacuum delivery should be preferred over forceps in the view of reduction of maternal perineal injuries. $^{21}$

Table 7: Rate of NICU admission in instrumental vaginal delivery

\begin{tabular}{|c|c|c|}
\hline Study done by & Country & Percentage \\
\hline Ourstudy & Nepal & $13 \%$ \\
\hline Singh Abha et al ${ }^{1}$ & India & $6.7 \%$ \\
\hline Prapas $\mathrm{N}$ et $\mathrm{al}^{20}$ & Greece & $14.4 \%$ \\
\hline Shameel Faisal et $\mathrm{al}^{13}$ & India & $27 \%$ \\
\hline
\end{tabular}

\section{CONCLUSION}

Instrumental vaginal delivery is an option to decrease the cesarean section rate with various maternal and fetal morbidities. So the decision to perform instrumental deliveries should be individualized and performed based on risks and benefits.

Instrumental vaginal delivery (Vacuum assisted vaginal delivery) is a key element of essential obstetric care whose role has often been undervalued. If performed by skilled trained persons it can be a safe alternative to cesarean section in second stage of labor with some maternal and perinatal morbidity.

\section{RECOMMENDATION}

Instrumental vaginal delivery (Vacuum assisted vaginal delivery) is an essential tool of obstetric emergency care. It is a safe alternative to reduce the rate of alarmingly increasing rate of cesarean section in second stage of labor. Although it has some maternal and fetal morbidity, it can be reduced if done by the experts.

The low rate of IVDs should be improved by training our residents in training on these procedures. Also, those who have learnt its usage, but are not using it any longer, should undergo training programme/workshops to update themselves. Long term affects such neurological deficits and intelligent quotients of infants and long term complications in mothers will highlight the safety of these procedures. Further prospective multicentre studies are needed for this. So every health professional involved in emergency obstetric care should have skill for application of instrumental vaginal delivery when needed.

\section{LIMITATION OF THE STUDY}

This study is a retrospective study. Therefore it is limited by factors that are known to influence the retrospective studies. We could have done prospective studies. The major factor which determines the safety of the instrument is the operator rather than the instrument. The knowledge regarding instrumental vaginal delivery among doctors may be limited or may vary. There is no fixed protocol for the vacuum assisted vaginal delivery. So the outcomes may vary depending on the performing doctor.

\section{ACKNOWLEDGEMENT}

We would like to acknowledge all the health professionals and patients who are involved in this study, without them this study wouldn't have been possible.

\section{CONFLICT OF INTEREST}

There is no conflict of interest.

\section{FUNDING}

Nil

\section{REFERENCES}

1) SAbha, R Pratibha. A Comparative Study of Feto - Maternal Outcome in Instrumental Vaginal Delivery.The Journal of Obstetrics and Gynecology of India. 2011; 61(6): 663-666.DOI 10.1007/s13224-0110119-3.

2) Groom KM, Jones BA, Miller N, Paterson-Brown S. A prospective randomised controlled trial of the Kiwi Omnicup versus conventional ventouse cups for vacuum-assisted vaginal delivery. BJOG 2006; 113:183-9. DOI: 10.1111/j.1471-0528.2005.00834.

3) Attilakos G, Sibanda T, Winter C, Johnson N, Draycott T. A randomized controlled trial of a new handheld vacuum extraction device.BJOG. 2005; 112: 1510-5.DOI: 10.1111/j.1471-0528.2005. 00729.

4) UNICEF, World Health Organization, UNFPA. Guidelines for monitoring the availability and use of obstetric services; 1997 . New York.

5) $C A$ Ameh, $A D$ Weeks. The role of instrumental vaginal delivery in low resource settings. BJOG An International Journal of Obstetrics and Gynaecology. 2009; 116: 22-25.DOI: 10.1111/j.14710528.2009.02331.

6) Chia CC, Huang SC. Third- and fourth-degree perineal laceration in vaginal delivery. Taiwan J ObstetGynecol 2012; 51:148-52. DOI: 10.1016/j.tjog.2012.01.035.

7) Hsieh WC, Liang CC, Wu D, Chang SD, Chueh HY, Chao AS. Prevalence and contributing factors of severe perineal damage following episiotomy-assisted vaginal delivery.Taiwan J Obstet Gynecol. 2014; 53:481-5.DOI: 10.1016/j.tjog.2013.07.002.

8) Aliya I, Aisha HK, Javaria NM. Vacuum and Forceps Deliveries; Comparison of Maternal and Neonatal Complications. Professional Med J. March 2008 15(1) 87-90.

9) Rubina $M$, Rozina M. Perinatal and Maternal outcome in ventouse versus forceps delivery. J Coll Physicians Surg Pak. 2002; 12 (6): 3457.PMID: 25452969.

10) Lamichhane $B$, Singh $A$. Changing trend of instrumental vaginal delivery at Patan hospital. NJOG. 2015; 10 (2): 33-35. DOI: https://doi.org/10.3126/njog.v13i3.23507

11) ACOG Practice Bulletin. Clinical management guidelines for obstetricians-gynecologists. Number 17. 2000. PMID: 15339790.

12) Aliyu LD, Kadas AS, Hauwa MA. Instrumental vaginal delivery in bauchi, northeast Nigeria. Journal of the west african college of surgeons. 2011; 1 (4): 18-27. PMID: 25452969.

13) Johanson R. Advances in assisted vaginal delivery with vacuum extractor.InBonnar J (Ed). Recent Advances in Obstetrics and Gynecology. Edinburg: Churchill Livingstone; 1998;125-139. 
14) Shameel Faisal, AmarjeetBava, Y. S. Nandanwar. Instrumental vaginal deliveries at tertiary centre.Int J Reprod Contracept Obstet Gynecol. 2016; 5(12): 4146-4150. DOI: http://dx.doi.org/10.18203/23201770.ijrcog20163997.

15) Chukwuemeka A, lyoke and Hyacinth E. Vacuum Deliveries at the University of Nigeria Teaching Hospital, Enugu. Trop J Obstet Gynaecol.2006; 23 (1), 23-26. DOI: org/10.4314/tjog.v.23i1.14560.

16) Maeve Eogan, Colmo'Herlihy. Safe use and enduring value of operative vaginal delivery. The Journal of Family Practice.June 2006; vol. 18 , No. 6 .

17) Ali UA, Norwitz ER. Vacuum assisted vaginal delivery. Rev Obstet Gynecol. 2009; 2(1): 5-17. PMID: 19399290
18) Ogunniyi SO, Sunusu YO. Instrumental vaginal delivery in Ile-Ife and Ilesha, Nigeria. Nig J Med. 1988; 7(3): 105-8.DOI: 10.4103/ TJOG.TJOG_51_18.

19) Murphy DJ, Liebling RE, Verity L, Swingler R, Patel R. Cohort study of the early maternal and Neonatal morbidity associated with operative delivery in the second stage of labour. Lancet. 2001; 358: 12037.PMID:11675055.

20) Prapas N, Kalogiannidis I, Masoura S. Operative vaginal delivery in singleton term pregnancies: short term maternal and neonatal outcomes. Hippokratia.2009; 13:41-5. PMID: 19240820.

21) Royal College of Obstetricians \& Gynaecologists. Instrumental vaginal delivery. Guideline No. 26. London: RCOG; 2005. 